\title{
NODULAÇÃO DA SOJA EM FUNÇÃO DA DESSECAÇÃO ANTECIPADA DE PASTAGEM
}

Rita de Cássia Lima Mazzuchelli ${ }^{1}$; Fabio Fernando de Araujo ${ }^{1}$; Eduardo Henrique Lima Mazzuchelli ${ }^{1}$; Eduardo Fabiano Romero²; Edemar Moro ${ }^{1}$

${ }^{1}$ Universidade do Oeste Paulista - UNOESTE, Programa de Pós Graduação em Agronomia, Presidente Prudente, SP. ${ }^{2}$ Engenheiro Agrônomo. E-mail: ritamazzuchelli@yahoo.com.br

\section{RESUMO}

O objetivo do trabalho foi avaliar a nodulação da soja em função da dessecação antecipada de pastagem degradada. O experimento foi instalado na fazenda experimental da Unoeste (220 28' $25^{\prime \prime}$, 51은 67' 88" W). A área estava ocupada com Urochloa brizantha (cv Marandu) com cinco anos de implantação. As parcelas foram constituídas por cinco épocas de dessecação da pastagem (150 DAS - dias antes da semeadura; 120 DAS; 60 DAS; 30 DAS e 15 DAS). A dessecação ocorreu com a aplicação do produto glyphosate, na dosagem de 5 litros ha ${ }^{-1}$. Aos 58 dias após a semeadura foram coletadas plantas para análises de número de nódulos na raiz principal, número de nódulos nas raízes laterais, massa seca de nódulos na raiz principal e massa seca de nódulos nas raízes laterais. As dessecações da pastagem em épocas mais antecipadas em relação à semeadura da soja, proporcionaram um ambiente mais favorável à simbiose Bradyrhizobium - soja com reflexos positivos no aumento da nodulação.

Palavras-chave: Glycine max, Rizóbio, Microbiologia, Fixação biológica de Nitrogênio, Integração Lavoura Pecuária.

\section{SOY NODULATION IN FUNCTION OF EARLY PASTURES DESICCATION}

\begin{abstract}
The objective was to evaluate the nodulation of soybean due to early drying of degraded pasture. The experiment was conducted at the experimental farm of Unoeste (22ㅇ 28 '25 "S, $51^{\circ} 67^{\prime} 88^{\prime \prime}$ W). The experimental area was busy with Urochloa brizantha (cv Marandu) with five years of implementation. The plots consisted of five periods of desiccation of pasture (150 DAS - days before sowing; 120 DAS; 60 DAS, 30 DAS and 15 DAS). The drying occurred with the application of glyphosate products, the dosage of 5 liters ha ${ }^{-1}$. After 58 days after sowing plants were collected for number of nodes analyzes the main root, number of nodes in the lateral roots, dry weight of nodules in the main root and dry mass of nodules on the lateral roots. The most anticipated pasture dessication in relation to soybean sowing provided a more favorable environment symbiosis Bradyrhizobium - soybean with positive effects in increasing nodulation.

Keywords: Glycine max, Rhizobium, Microbiology, Biological Nitrogen Fixation, Integration Crop Farming.
\end{abstract}


INTRODUÇÃO

A sojicultura se tornou um dos mercados agroalimentares mais importantes no cenário agroindustrial mundial. A soja é a oleaginosa mais produzida e consumida no mundo e isto se deve a sua ampla utilização, que pode ser tanto para consumo humano quanto para o consumo animal, além do uso na fabricação de bicombustíveis, caracterizando-a como uma das principais commodities agrícolas. Devido à importância do grão para a economia do país e a sua crescente demanda externa, o plantio da oleaginosa ocorre em quase todas as regiões do Brasil (CASTRO; VIANA, 2013).

No desenvolvimento da cultura da soja (Glycine max (L.) Merrill), um importante componente químico necessário para o desenvolvimento das plantas é o nitrogênio. Este elemento pode ser obtido através do solo, por meio da decomposição da matéria orgânica ; através dos fertilizantes nitrogenados, bem como, da fixação química do $\mathrm{N}_{2}$ em descargas elétricas e, ainda, por meio da fixação biológica do nitrogênio atmosférico, que ocorre pela associação simbiótica com estirpes de Bradyrhizobium japonicum e B. elkanii (CAMPOS; HUNGRIA, TEDESCO, 2001).

As bactérias do gênero Bradyrhizobium, quando em contato com as raízes da soja, infectam as mesmas através dos pêlos radiculares, formando os nódulos. O processo de fixação biológica do nitrogênio, dependendo de sua eficiência, pode fornecer todo o $\mathrm{N}$ que a soja necessita para o seu desenvolvimento (EMBRAPA, 2004). A fixação biológica de nitrogênio (FBN) representa um dos principais fatores de competitividade da cultura da soja para o país (ZILLI et al., 2008).

Existe sempre uma necessidade do estabelecimento de novos patamares de produtividade, tendo em vista a necessidade de recuperação de áreas degradadas, a viabilização econômica e o incremento da diversidade de culturas que demandam políticas agrícolas e estratégias de pesquisa inovadoras (HUNGRIA; CAMPO; NOGUEIRA, 2014).

O objetivo do trabalho foi o de avaliar a nodulação da soja em função da dessecação antecipada de pastagem degradada.

\section{METODOLOGIA}

O experimento foi conduzido na Fazenda Experimental da Unoeste, localizada no município de Presidente Bernardes-SP, em um solo classificado como Argissolo Vermelho distroférrico (EMBRAPA, 2006). A localização da área experimental é definida pelas coordenadas geográficas:

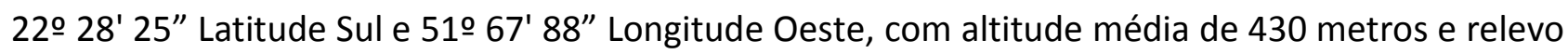
suave ondulado. 
A área experimental estava ocupada com a espécie Urochloa brizantha (cultivar Marandú) com cinco anos de implantação, porém com baixa capacidade de produção de forragem e baixa capacidade de suporte animal. Realizou-se a caracterização química do solo até a profundidade 0$20 \mathrm{~cm}$. Os valores obtidos foram: matéria orgânica, $14 \mathrm{~g} \mathrm{dm}^{-3}$; $\mathrm{pH}(1: 2,5$ solo/suspensão de $\mathrm{CaCl} 2$ 0,01 $\mathrm{mol} \mathrm{L}^{-1}$ ), 5,2; $\mathrm{P}$ (resina), 1,7 $\mathrm{mg} \mathrm{dm}^{-3} ; \mathrm{K}, \mathrm{Ca}$ e $\mathrm{Mg}$ trocáveis de 0,9, 10,1 e 9,1 mmolc dm ${ }^{-3}$, respectivamente, acidez total em pH 7,0 $(\mathrm{H}+\mathrm{Al})$ de 19,6 mmolc $\mathrm{dm}^{-3}$, capacidade de troca de cátions total (CTC) de 39,6 mmolc dm ${ }^{-3}$, saturação por bases de 50,6. Quanto aos micronutrientes os valores para $\mathrm{Fe}, \mathrm{Cu}, \mathrm{Mn}, \mathrm{Zn}$ e $\mathrm{B}$ foram 19,3; 2,0; 2,1; 0,8 e 0,16 $\mathrm{mg} \mathrm{dm}^{-3}$, respectivamente. Foram aplicados na área 2,0 $\mathrm{t} \mathrm{ha}^{-1}$ de calcário dolomítico e 1,0 ton $\mathrm{ha}^{-1}$ de gesso (RAIJ et al., 1997), anteriormente à implantação do experimento.

O delineamento experimental foi em faixas, constituídas por cinco épocas de dessecação da pastagem (150 DAS - dias antes da semeadura; 120 DAS; 60 DAS; 30 DAS e 15 DAS). Cada faixa possuía 10 metros de largura por 40 metros de comprimento, sendo espaçadas uma das outras por 2 metros. A dessecação das faixas experimentais ocorreu com a aplicação do produto glyphosate, na dosagem de $5 \mathrm{Lha}^{-1}$, com volume de calda de $250 \mathrm{Lha}^{-1}$.

A cultivar de soja utilizada foi a TMG 1264 RR, a qual foi semeada em 29 de novembro de 2014. O tratamento de semente foi realizado com os agroquímicos Standak ${ }^{\circledR}$ e Maxim $\mathrm{XL}^{\circledR}$, que continham as estirpes SEMIA 5019 (Bradyrhizobium elkanii) e SEMIA 5079 (Bradyrhizobium japonicum) com 5 bilhões de células viáveis $\mathrm{ml}^{-1}$, nas dosagens recomendada pelos fabricantes. A adubação de semeadura foi realizada com a aplicação de $250 \mathrm{~kg} \mathrm{ha}^{-1}$ da formulação 04-30-10. Realizou-se também uma adubação de cobertura com cloreto de potássio, no dia 27 de dezembro de 2014, aos 20 DAE (dias após a emergência) na dosagem de $125 \mathrm{~kg} \mathrm{ha}^{-1}$.

Aos 58 dias após a semeadura foram coletadas 15 plantas por repetição, com quatro repetições, totalizando 60 plantas por tratamento, para análises de número de nódulos na raiz principal, número de nódulos nas raízes laterais, massa seca de nódulos na raiz principal e massa seca de nódulos nas raízes laterais.

Os dados foram submetidos à análise de variância, sendo utilizada a análise da regressão, observando-se na escolha do modelo a significância dos parâmetros da equação e os valores do $R^{2}$.

\section{RESULTADOS}

A massa de nódulos na raiz principal da soja apresentou comportamento linear crescente, conforme houve aumento dos dias da dessecação da pastagem. A dessecação realizada aos 150 
DAS promoveu incrementos de $60 \%$ na nodulação da soja, quando comparada à dessecação mais tardia aos 15 dias antes da semeadura da cultura (Figura 01).

A massa de nódulos nas raízes laterais apresentou comportamento linear crescente com o aumento do período da dessecação da pastagem. A dessecação aos 150 DAS promoveu aumentos de $44 \%$ na massa de nódulos nas raízes laterais quando comparada à dessecação aos 15 DAS (Figura 02).

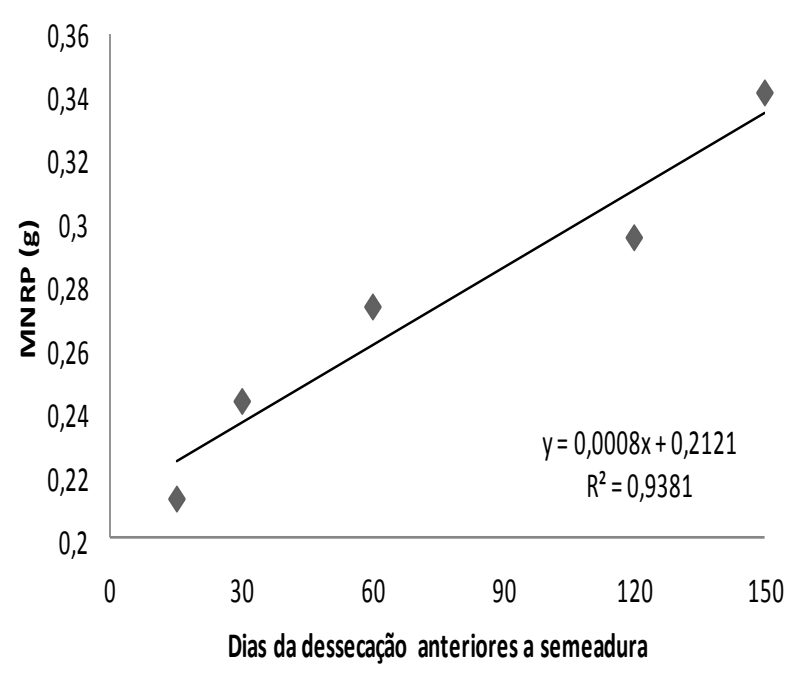

Figura 1. Massa de nódulos na raiz principal MNRP de soja (gramas), em função da dessecação realizada em diferentes épocas anteriores à semeadura.

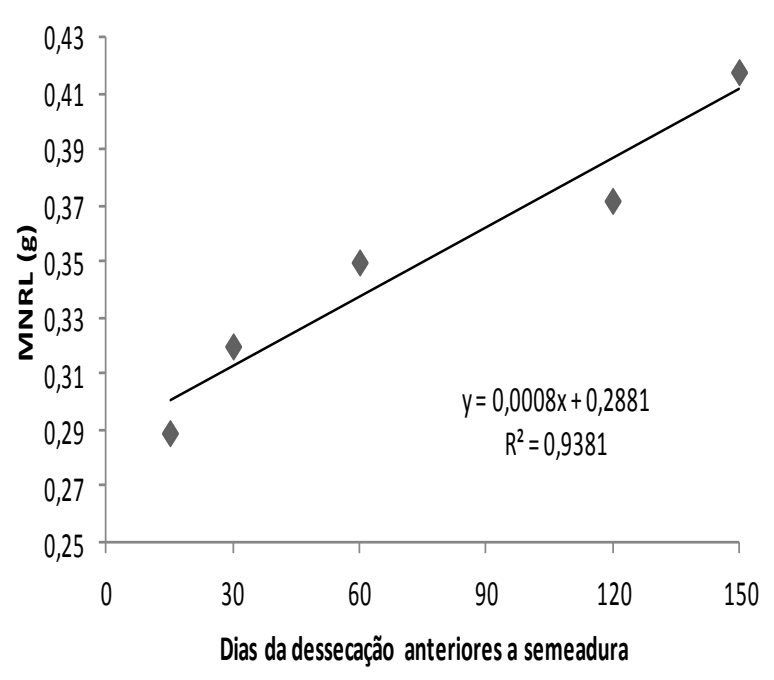

Figura 2. Massa de nódulos nas raízes laterais - MNRL de soja (gramas), em função da dessecação realizada em diferentes épocas anteriores a semeadura.

Em relação ao número de nódulos na raiz principal, podemos observar o comportamento linear crescente em resposta ao período de dessecação da pastagem (Figura 3). O mesmo padrão linear crescente foi observado nos nódulos das raízes laterais, sendo que quanto mais longo o período de dessecação anterior ao cultivo da soja, maior é a nodulação das plantas (Figura 4). 


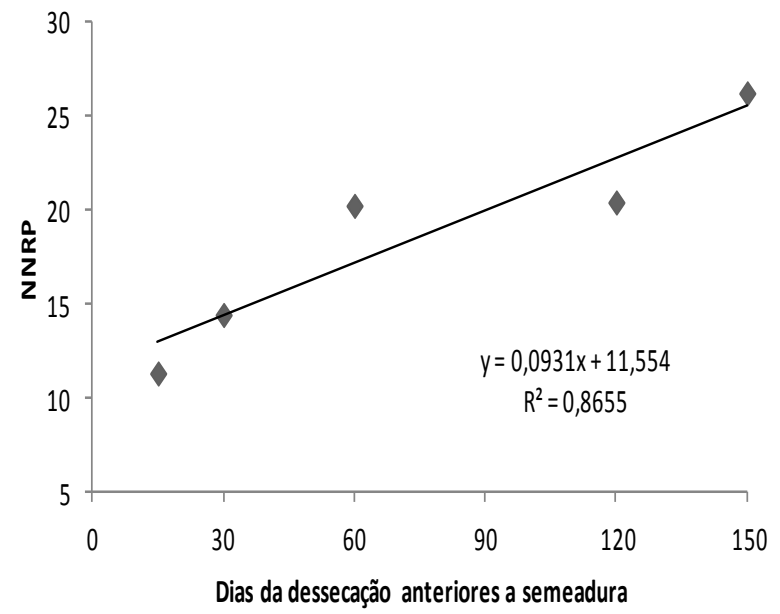

Figura 3. Número de nódulos na raiz principal - NNRP de soja em função da dessecação realizada em diferentes épocas anteriores à semeadura.

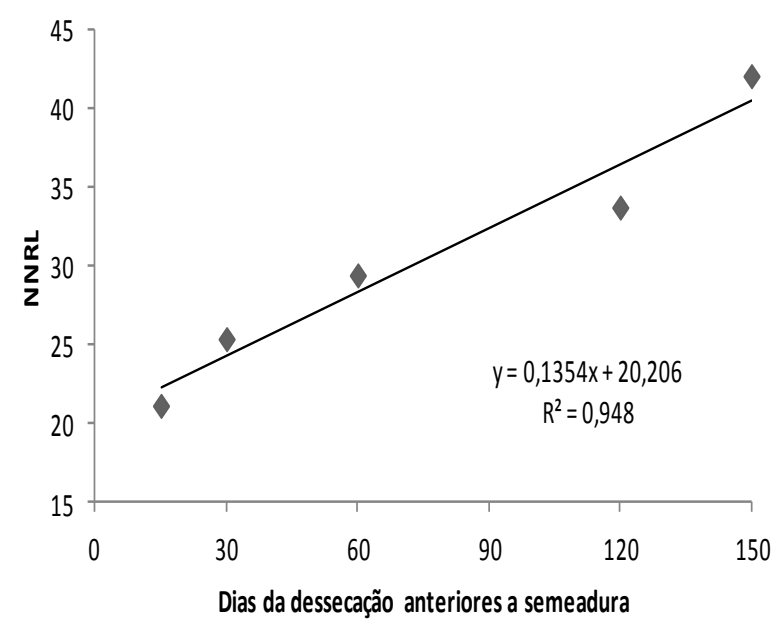

Figura 4. Número de nódulos nas raízes laterais - NNRL de soja em função da dessecação realizada em diferentes épocas anteriores à semeadura.

\section{DISCUSSÃO}

Em solos onde não foi realizado o cultivo de soja, como é o caso desta área experimental, os valores de nodulação das plantas tendem a serem inferiores em relação a solos com histórico do cultivo da leguminosa, devido à permanência das bactérias no solo. Entretanto, é importante que se realize a cada ciclo produtivo novas inoculações, já que as estirpes inoculadas tendem a ser mais eficientes na formação dos nódulos em relação às bactérias sobreviventes no ambiente (SANTOS et al., 2013).

Para a boa produtividade da cultura da soja é importante que esta apresente uma nodulação eficiente em número e massa de nódulos, já que estes estão diretamente relacionados à capacidade de fixação biológica do nitrogênio. Brandelero, Peixoto e Ralisch (2009), estudando a nodulação de cultivares de soja e seus efeitos no rendimento de grãos, observaram que a produtividade da soja apresentou correlação positiva com o número e a massa de nódulos da cultura.

Pode-se atribuir a maior nodulação ao maior período de dessecação da pastagem, pela permanência de resíduos vegetais sendo decompostos na área, proporcionando maior material orgânico em decomposição, resultando um ambiente mais favorável ao estabelecimento e colonização radicular pelas células bacterianas do Bradyrhizobium (CAMPOS et al., 2001).

Além disso, por se tratar de uma área cultivada com soja em primeiro ano, a população de microssimbiontes com a capacidade de nodulação de soja presentes no solo é baixa ou até mesmo nula. Desta forma, o efeito de toxicidade provocada por algum componente químico, como no 
caso, a utilização do herbicida glyphosate, em curto período de tempo, pode resultar em uma redução das bactérias inoculadas na semeadura, diminuindo consequentemente a massa e o número de nódulos das raízes da soja (COSTA et al., 2013).

Reis et al. (2014) observaram redução no número e massa de nódulos de soja quando utilizou-se o herbicida glyphosate, atribuindo a diminuição da nodulação das plantas aos sais presentes na formulação do produto, que comprometem os microrganismos do solo.

\section{CONCLUSÃO}

As dessecações da pastagem mais antecipadas em relação à semeadura da soja proporcionaram um ambiente mais favorável à simbiose Bradyrhizobium - soja, com reflexos positivos no aumento da nodulação.

\section{REFERÊNCIAS}

BRANDELERO, E. M.; PEIXOTO, C. P.; RALISCH, R. Nodulação de cultivares de soja e seus efeitos no rendimento de grãos. Semina: Ciências Agrárias, v. 30, n. 3, p. 581-588, 2009.

http://dx.doi.org/10.5433/1679-0359.2009v30n3p581

CAMPOS, B. C.; HUNGRIA, M.; TEDESCO, V. Eficiência da fixação biológica de $\mathrm{N}_{2}$ por estirpes de Bradyrhizobium na soja em plantio direto. Revista brasileira de ciência do solo, v. 25, n. 3, p. 583592, 2001. http://dx.doi.org/10.1590/S0100-06832001000300007

CASTRO, A. P.; VIANA, J. G. A. Evolução da Produção de Soja no Rio Grande do Sul: Um Comparativo entre Mesorregiões do Estado. Anais do Salão Internacional de Ensino, Pesquisa e Extensão, v. 5, n. 2, 2013.

COSTA, M. R. et al. Sobrevivência de Bradyrhizobium japonicum em sementes de soja tratadas com fungicidas e os efeitos sobre a nodulação e a produtividade da cultura. Summa Phytopathologica, Botucatu, v. 39, n. 3, p. 186-192, 2013

EMBRAPA. Fixação biológica de nitrogênio (FBN). 2004. Disponível em:

<http://agrosustentavel.com.br/downloads/fbn.pdf> Acessado em: 29 out. 2014.

EMBRAPA. Centro Nacional de Pesquisa de Solos. Sistema Brasileiro de Classificação de Solos. 2 ed. Rio de Janeiro: Embrapa Solos, 2006.

HUNGRIA, M.; CAMPO, R. J.; NOGUEIRA, M. A. A pesquisa em Fixação Biológica do Nitrogênio na Embrapa Soja: passado, presente e perspectivas futuras. In: Embrapa Soja-Artigo em anais de congresso (ALICE). In.: Reunião da rede de laboratórios para recomendação, padronização e difusão de tecnologia de inoculantes microbianos de interesse agrícola, 16., 2012, Londrina. Anais... Londrina: Embrapa Soja, 2014.

RAIJ, B. V. et al. Recomendações de adubação e calagem para o Estado de São Paulo. 2.ed. rev. e atual. Campinas: Instituto Agronômico/Fundação IAC, 1997. 285p. (Boletim Técnico, 100). 
REIS, M. R. et al. Mycorrhizal colonization, nodulation and yield of roundup ready soybeans after applying different formulations Glyphosate. Planta Daninha, v. 32, n. 3, p. 563-569, 2014. http://dx.doi.org/10.1590/S0100-83582014000300012

SANTOS, E. L. et al. Competitividade nodular de estirpes de Bradyrhizobium spp. em cultivares de soja sob diferentes disponibilidades hídricas. Global Science and Technology, Rio Verde, v. 06, n. 03, p. 116-123, dez. 2013.

ZILLI, J. É. et al. Notas Científicas Inoculação de Bradyrhizobium em soja por pulverização em cobertura. Pesquisa agropecuária brasileira, Brasília, v. 43, n. 4, p. 541-544, 2008. 